\title{
Research Paper: Modeling the Effect of Family Atmo- sphere, School Atmosphere, and Social Support on Aggressiveness and Addiction Preparedness Among Students: The Mediating Role of Extroversion
}

\author{
Zohre Shahriari Shaghaghi $^{1}$ (D, Afsaneh Ghanbaripanah ${ }^{1^{*}}$ (D), Parisa Tajalli ${ }^{1}$ (D)
}

1. Department of Psychology, Faculty of Psychology and Social Sciences, Central Tehran Branch, Islamic Azad University, Tehran, Iran.

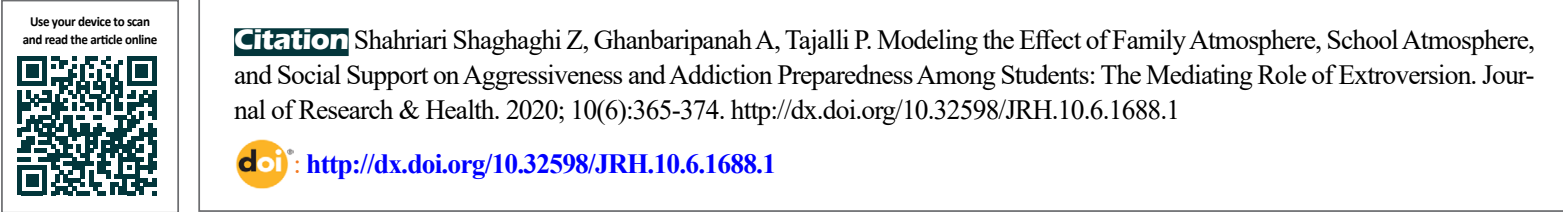

\section{(c) (i) (\$)}

Article info:

Received: 30 Apr 2019

Accepted: 24 Dec 2019

Publish: 01 Nov 2020

\section{Keywords:}

Family, Social support, Aggression, Addiction, Extroversion

\section{A B S T RACT}

Background: The increased rates of aggression and drug abuse among students are considered an important health issue. Therefore, the present study aimed to investigate the relationship between the emotional atmosphere of the family, the school climate, perceived social support, aggressive behavior, and preparedness for addiction among students, considering the mediating role of extroversion.

Methods: This research used the analytical-correlative method. Also, the statistical population included all high school students in Tehran, during the academic year of 2017-2018.

Results: The school environment had a significant direct effect on the preparedness for addiction. Besides, we identified the indirect effect of the school environment on irregular drug addiction. The hypothesized model showed the full effect and the nonsignificant direct effect of perceived social support on aggressive behavior. Moreover, there was a significant indirect effect between perceived social support and aggressive behavior. However, there was no direct or indirect effect between perceived social support and preparedness for addiction and the existence of extroversion's mediating function.

Conclusion: Thus, teachers and school administrators are recommended to discuss the psychological environment of the family, the school atmosphere, and perceived social support.

\footnotetext{
* Corresponding Author:

Afsaneh Ghanbaripanah, PhD.

Address: Department of Psychology, Faculty of Psychology and Social Sciences, Central Tehran Branch, Islamic Azad University, Tehran, Iran Phone: +98 (912) 2972779

E-mail:af ghanbary@yahoo.com
} 


\section{Introduction}

dolescence is an important and sensitive period of everyone's life and can be affectA ed by various factors. Family relationships, peer groups, and the social environment, in which teenagers grow up are important factors that influence their emotional development and personality [1]

Moreover, aggressive behaviors and readiness for substance dependency among adolescents and youth are two fundamental factors that create many fundamental, cultural, political, economic, and health issues, in contemporary societies. Numerous studies reported that the emotional atmosphere of the family affects the mental and behavioral health of children. Also, youths with secure attachments experience less drug use [2]. The most common causes of individual psychological conditions, such as stress desire to escape, and drug abuse are related to family life and social activity [3]. Children who feel to be threatened by their parents will react by hostility to protect themselves from such threats [4].

In addition to the emotional atmosphere of the family, the school atmosphere can cultivate aggressive behaviors and preparation for addiction among adolescents. All views on the classroom environment or the organizational culture of the university rely on the Lewin theory. He concluded that one should pay attention to the whole scenario in which the action happens to understand human behavior. The word "whole position" refers to an individual and his/her environment [5].

Accordingly, in Turkey, Kaya [6] and Kimon [7] conducted two separate studies, both of which point to the role of the school atmosphere in aggressive behavior. Also, Estevez [8] highlighted the atmosphere of family and school and the role of sex in making aggressive behaviors among adolescents, in Spain. Besides, school performance was negatively correlated with the frequency of violent behavior among adolescents, in a longitudinal study conducted in the United States [9].

Moreover, according to previous studies, perceived social support is another variable associated with aggressive behaviors and readiness for addiction. Perceived social support, such as resources provided by others, gives the person a sense of worthiness [10].

In Iran, Bayrami et al. found that the scores of people in perceived social support and the feeling of social and emotional loneliness were significantly associated with internet addiction [11]. In other words, the status of people with internet addiction was unsuitable in terms of perceived social support and the feeling of social and emotional loneliness. Furthermore, Riahi et al. [12] reported a direct and significant relationship between the level of social support and mental health.

Studies have shown that personality traits can also lead to adolescent's preparation for violence and addiction. Over the past 30 years, a significant number of researchers have examined the cognitive, behavioral, and physiological response scales concerning extroversion [4]. In general, studies approved the Eysenck assumption [13], arguing that introverts are more reactive than extroverts and they have lower thresholds.

The abovementioned and similar studies only addressed the role of one or two variables in predicting aggressive behaviors or readiness for addiction. Also, no cohesive study investigated the relationship between several predictor variables, such as the emotional atmosphere of the family, the atmosphere of the school, and perceived social support with the mediating role of the dimensions of extroversion, among males and females. Adolescence is a sensitive stage of life, and adolescents play an important role in a country's future. Besides, the relationship between the abovementioned variables leads to the creation of aggressive behaviors and readiness for addiction in this age group. Therefore, considering the corresponding theoretical and research foundations, it makes sense to model the impact of the emotional atmosphere of the family and the school atmosphere on aggressive behaviors and readiness for addiction. Thus, this study aimed to evaluate two hypotheses:

- The structural model of the impact of the family's emotional atmosphere, the school atmosphere, and perceived social support on the aggressive behavior and addiction readiness has a suitable fitness among students.

- The structural model of the impact of the family's emotional atmosphere, the school atmosphere, and perceived social support on the aggressive behavior and addiction readiness has a suitable fitness among students, considering the mediating role of introversion-extroversion.

\section{Methods}

This research was an analytical and correlational study with the structural equation modeling method. The statistical population included all (a total number of 224 401 students) high school students in Tehran, in the academic year of 2017-2018. In this regard, Hair et al. 
[14] proposed a sample size range of 100 to 400, with a minimum ratio of $5: 1$ between cases and variables [14]. Thus, after obtaining the necessary permits from the Ministry of Education, 485 male and female students were selected from five parts of north, south, east, west, and center of Tehran. Two high schools were selected from each part (one high school for boys and one high school for girls). Therefore, a total number of 10 high schools were randomly selected, also, three classes were randomly selected in each high school, at the grades of 10,11 , and 12 . Next, the questionnaires were distributed among them. Using the questionnaires, the field data collection method was used, also, the research background was obtained using a library method. We separately presented the research findings, including the participants' descriptive statistics and demographic information. The obtained data were evaluated using EMOS software version 24 and SPSS V. 25.

The following measurement tools were used in the present study.

Eysenck and Wilson developed the aggression questionnaire, in 1975 [15]. In Iran, this questionnaire was standardized and validated by Kaviani et al. [15]. Their results showed the correlation coefficients of 0.81 for extroversion, 0.76 for psychosis, 0.88 for neuroticism, 0.93 for the tendency to addiction, 0.93 for the tendency to crime, and 0.95 for the tendency to the violation. Also, the internal consistency of each of these subscales was calculated using the Cronbach alpha with the following Results: 0.79 for extroversion, 0.76 for psychosis, 0.86 for neuroticism, 0.74 for the tendency to addiction, 0.75 for the tendency to crime, and 0.71 for the tendency to the violation. The validity of this scale is of the type of content [15].

The addiction readiness scale was developed by Weed and Butcher, in 1992. The Persian version of this scale was developed by Zarger, based on the mental-social conditions of Iranian society [16]. Using the Cronbach alpha, the reliability of 0.90 was calculated for this scale. Also, the alpha value for the first (active) and second (passive) factors was calculated as 0.91 and 0.75 , respectively [17].

The Eysenck personality questionnaire was developed by Eysenck, in 1974, and originally paid attention to two fundamental components, including extroversion and psychosis in the measurement of personality [15]. The internal consistency of the questionnaire's scales is quite satisfactory. The Cronbach alpha coefficients for the components of extroversion, neuroticism, and lying are from $79 \%$ to $85 \%$; this coefficient is in the range of $68 \%$ to $74 \%$ for psychosis. The reliability of the components of extroversion, neuroticism, and lying was calculated as 0.8 to 0.9 through a test-retest within one month, for ordinary people; the reliability was in the range of 0.71 to 0.83 for the psychosis component [17]. Also, the validity of this questionnaire was confirmed in a study conducted on the standardization of the Eysenck Personality Questionnaire among the students of Tehran's universities [18].

The Family's Emotional Atmosphere Questionnaire was developed by Hilburn, in 1964 [19]. This questionnaire measures eight aspects, including love, cuddling, confirming, shared experience, gift-giving, encouraging, trusting, and feeling secure [19]. Kouti et al. [20] used the affective family communication questionnaire to determine the concurrent validity of the family's emotional atmosphere questionnaire. They calculated a validity coefficient of 0.67 for this questionnaire. Besides, Askari et al. [3] used the Cronbach alpha, the split-half, and the Gutman reliabilities with the results of $0.85,0.77$, and 0.77 , respectively, for the internal consistency of the family's emotional atmosphere questionnaire. These results indicate the acceptable reliability of this scale.

The questionnaire of class and school environment was developed by Rovai et al. in 2004 to measure students' emotions against the school environment. In general, this questionnaire measures the degree of the students' admission to the school and their acceptance of the school environment. The Cronbach alpha coefficient for class form and school form was reported to be 0.84 and 0.83 , respectively. Also, the internal consistency coefficients for the two social and learning dimensions of class form and school form were 0.90 and 0.87 , and 0.85 and 0.82 , respectively. A reliability of 0.91 was calculated for this questionnaire using the Pearson correlation coefficient with a 2-week interval [21].

The multidimensional scale of perceived social support: This scale is a subjective evaluation of the social support adequacy, developed by Zimmet et al., in 1998. This scale assesses the perceptions of social support in three sources, including "family", "friends", and "others". The Cronbach alpha reliability coefficient for the scale as a whole was calculated as 0.93 and for the scales of family, friends, and others' social support was calculated as $0.91,0.89$, and 0.91 , respectively [22].

\section{Results}

Out of 485 respondents, 240 were girls (49.5\%) and 245 were boys $(50.5 \%)$, based on the descriptive statistics. Also, the frequency of respondents differs by age category. Accordingly, 38, 153, 218, 71, and 5 respondents 


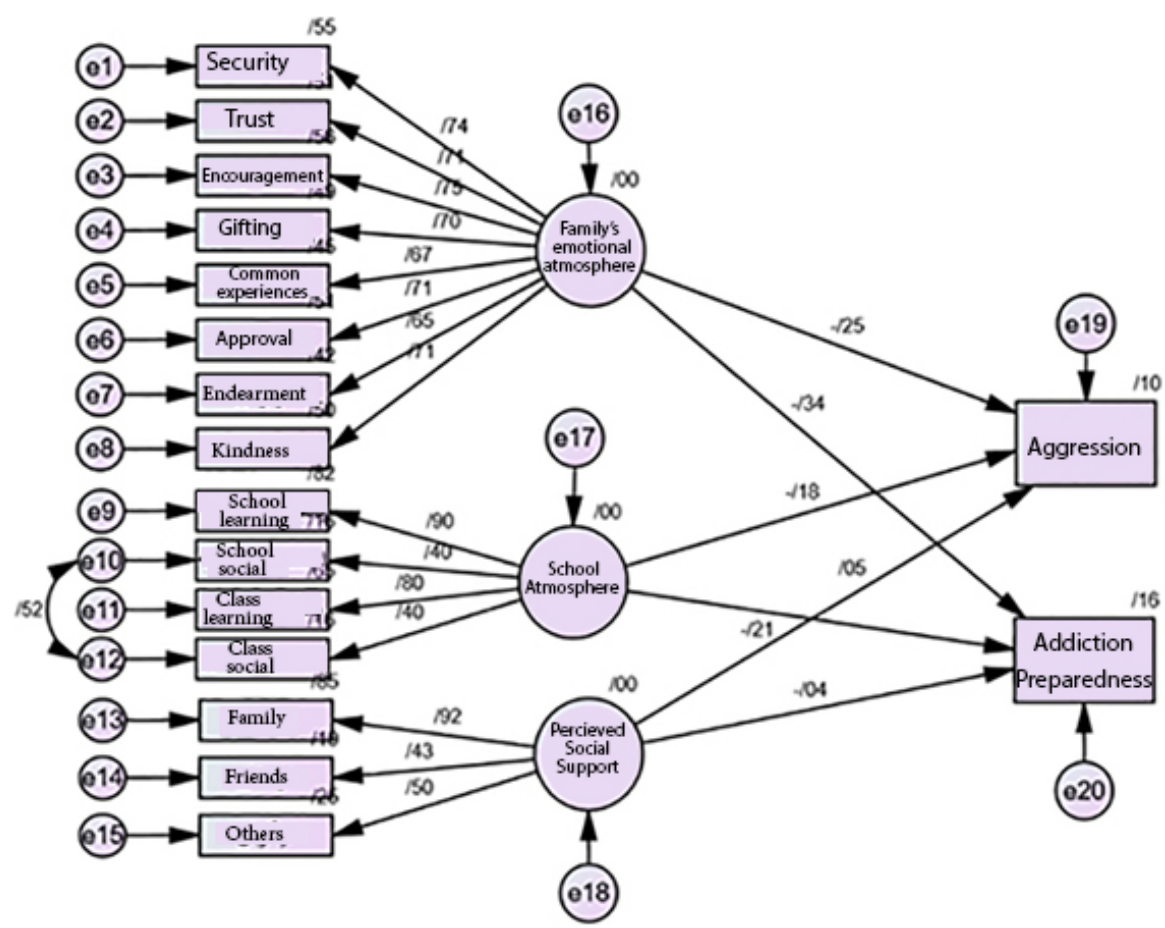

IMPE

Figure 1. Structural equations model proposed for the effect of the family atmosphere, school atmosphere, and perceived social support on aggression and addiction readiness

$(7.8 \%, 31.5 \%, 44.9 \%, 14.6 \%$, and $1.0 \%$, respectively) were aged 15 years, 16 years, 17 years, 18 years, and 19 years, respectively. Thus, the most common age was 17 years with 218 participants, and the least belonged to the age of 19 years with five participants. Before the analysis, the data of all variables were screened; the assumption of violating the pertinent data was investigated, and it was ensured that no pertinent data affected the results.

The results for Hypothesis 1 are as follows: the effect of the family emotional atmosphere, the school atmosphere, and perceived social support on aggressive behavior and readiness for addiction were studied in the section on inferential statistics. The relationships between each pair of variables were examined, in addition to the fitness of this model.

Figure 1 presents the proposed model for the direct effects between the study variables; the standard path coefficients and model's fitness indices are calculated. The factor loading ranges from -0.041 to 0.92 , and the SMC ranges from 0.097 to 0.84 . Also, Table 1 represents the results of the statistical scales of fitness indices, including the Ooodness of Fit (GOF); these results are explained as follows:

At the significance level of 0.000 , the chi-square test was significant, and the value of CMIN/df was 3.100. The Comparative Fit Index (CFI) was 0.916, which was acceptable because it was above 0.90 . Furthermore, the Incremental Fit Index (IFI) value was 0.916, which was appropriate because it was higher than 0.90, suggesting satisfactory fitness. Also, the Root Mean Square Error of Approximation (RMSEA) of 0.066 is excellent; according to McCalumn et al. [23], if the value of this index is lower than 0.1 , the model's fitness will be excellent. If it is between 0.1 and 0.5 , the model's fitness will be good, and in the range of 0.5 to 0.8 , the fitness will be normal.

The effect between the emotional atmosphere of the family and aggressive behavior is significant in the assumed model with a standardized path rate of 0.246 and the $t$ value of 0.001 at $\mathrm{P}=0.001$. Also, significant is the effect of the emotional atmosphere of the family on the readiness for addiction with a standardized path rate of

Table 1. Fitness indices of structural equations model

\begin{tabular}{cccccccc}
\hline Chi-square & DF & $\mathbf{P}$ & CMIN/DF & GFI & IFI & CFI & RMSEA \\
\hline 353.393 & 114 & 0.000 & 3.100 & 0.922 & 0.916 & 0.916 & 0.066 \\
\hline
\end{tabular}




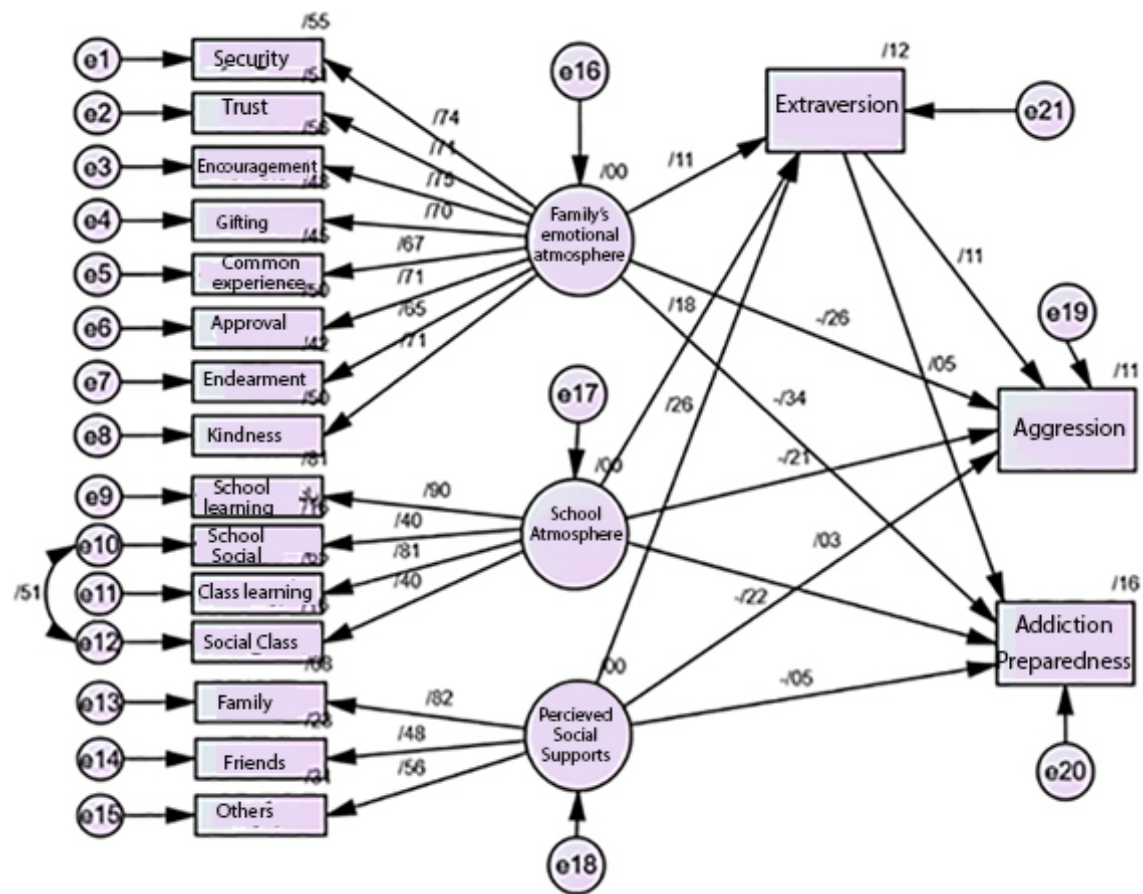

nRe

Figure 2. Structural equations model of the effect of family's emotional atmosphere, school atmosphere, and perceived social support on aggressive behavior and addiction readiness with the mediating role of extroversion

-0.335 , and the $t$ value of -6.377 at $\mathrm{P}=0.001$. Regarding the effect of the school environment on aggressive behavior and preparation for dependence, we obtained a standardized path rate of -0.184 and -0.208 and a t-value of -3.481 and -3.977 , respectively, both cases are relevant at $\mathrm{P}=0.001$. Ultimately, the perceived social support variables could not predict aggressive behavior and preparation for dependence, despite the standardized regression coefficient. Table 2 shows the results of the standardized paths between the variables and their level of significance. As above, Figure 1 depicts the assumed model with standardized coefficients.

This chapter considers the mediating role of extroversion in the relationship between the psychological atmo- sphere of the parents, the school atmosphere, perceived social support, aggressive behavior, and readiness for addiction. Similar to the model of the previous hypothesis, fitness and adequacy are investigated. The findings for Hypothesis 2 are as follows:

The factor loading range of standardized coefficients was between -0.049 and 0.89 and the SMC range was between 0.000 and 0.80 (Figure 2). Table 3 reports the results of the statistical fitness indices, including GOF. The chi-square was significant at the level of 0.000 and the value of CMIN/df was equal to 3.100. The CFI was 0.911 , it was acceptable because it was higher than 0.90 . Also, IFI had a value of 0.910 , which was also acceptable because it is higher than 0.90 , indicating a suitable

Table 2. Direct effects between independent and dependent variables in the assumed model

\begin{tabular}{|c|c|c|c|c|}
\hline Relationships & Standardized Coefficients & Standard Error & Critical Point & $\mathbf{P}$ \\
\hline Family's emotional atmosphere -> aggression & -0.246 & 0.335 & -4.917 & 0.001 \\
\hline Family's emotional atmosphere -> addiction & -0.335 & 0.873 & -6.737 & 0.001 \\
\hline School's atmosphere -> aggression & -0.184 & 0.244 & -3.481 & 0.001 \\
\hline School's atmosphere -> addiction & -0.208 & 0.603 & -3.977 & 0.001 \\
\hline Perceived Social Support -> aggression & 0.052 & 0.259 & 1.059 & 0.290 \\
\hline Perceived Social Support -> addiction & -0.041 & 0.632 & -0.857 & 0.392 \\
\hline
\end{tabular}


Table 3. Perfect, direct, and indirect effects between variables and the result of the mediating effect of extroversion

\begin{tabular}{|ccccc}
\hline \multicolumn{1}{c}{ Relationships } & Perfect Effect (P) & Direct Effect (P) & Indirect Effect (P) & Result \\
\hline Family's emotional atmosphere -> aggression & $-0.248(0.001)$ & $-0.260(0.001)$ & $0.012(0.041)$ & Partly mediating \\
\hline Family's emotional atmosphere -> addiction & $-0.336(0.001)$ & $-0.342(0.001)$ & $0.006(0.276)$ & Direct effect \\
\hline School's atmosphere -> aggression & $-0.187(0.001)$ & $-0.342(0.001)$ & $0.006(0.276)$ & Partly mediating \\
\hline School's atmosphere -> addiction & $-0.208(0.001)$ & $-0.218(0.001)$ & $0.010(0.262)$ & Direct effect \\
\hline Perceived social support -> aggression & $0.062(0.257)$ & $0.032(0.592)$ & $0.014(0.014)$ & Indirect effect \\
\hline Perceived social support -> addiction & $-0.035(0.554)$ & $-0.049(0.429)$ & $0.030(0.265)$ & Without effect \\
\hline
\end{tabular}

fitness. The RMSEA value of 0.062 also indicates the model's fitness. Fitness index results were as follows: chi-square: 390.302; DF: 126; P: 0.000; CMIN/df: 3.098; GFI: 0.920; IFI: 0.910; CFI: 0.911; RMSEA: 0.062.

Concerning the results of fitness indices, we obtained the structural equations model of the impact of the emotional atmosphere of the parents, the school atmosphere, and perceived social support on aggressive behavior and readiness for addiction with the mediating role of extroversion (Figure 2).

The perfect effect of the psychological atmosphere of the family on total aggression activity $(-0.248)$ was significant (Table 3$)$. Also, the direct effect $(-0.260)$ and the indirect effect $(0.012)$ of this factor, with the mediating function of extroversion, were significant. According to Parker et al. [24], these results imply that extraversion partially plays a part in the relationship between the emotional atmosphere of the family and aggressive behaviors.

The psychological atmosphere of the family showed a significant relationship with readiness for addiction, including a perfect effect (-0.0336) and an indirect effect $(-0.342)$. Nevertheless, this indirect effect was stated to be negligible between the emotional atmosphere of the family and readiness for addiction (0.006). According to Parker et al. [24], this result suggests that there is only one direct effect here; as a mediator, extraversion does not play a role in determining the emotional atmosphere of the family and preparation for addiction.

Concerning the atmosphere of the school and its impact on aggressive behavior, it was found that the atmosphere of the school had a substantial perfect effect $(-0.187)$ on aggressive behavior, as well as a direct $(-0.208)$ and indirect $(0.021)$ effect with the mediating role of extroversion.
In other words, extroversion may mediate in predicting the environment of school through aggressive behavior.

Also, the study of the atmosphere of school with readiness for addiction showed a perfect effect $(-0.208)$ and a direct effect $(-0.218)$ between these variables. However, it was reported that the indirect impact between the atmosphere of school and readiness for addiction (0.010) was insignificant. It suggests that there is only one direct effect here, and extraversion does not play a mediating role in predicting the school atmosphere and the readiness for addiction.

Also, the results of the assumed model showed an insignificant perfect effect (0.662) and a direct effect (0.232) between perceived social support and aggressive behavior. The indirect effect between perceived social support and aggressive behavior (0.014) also showed that such a relationship is important, namely that here we have only a kind of indirect effect, and that extraversion as a mediator has no role to play in the prediction of perceived social support with aggressive behavior.

Finally, concerning the effect of perceived social support with readiness for addiction, no perfect, direct, and indirect effects were seen with/without extroversion's mediating role. Table 3 shows the results of the relationships between variables and the related findings.

\section{Discussion}

Statistical analysis showed a negative correlation between the psychological atmosphere of the family and violence, providing the first hypothesis. This conclusion is also confirmed by previous research. The findings of another study indicate a significant relationship between the psychological atmosphere of the family and the aggressive behavior of high school boys [24]. Moreover, a 
study investigated the factors and roots of behavioral aggression among high school students in Azarshahr. The result showed that the aggression of parents and the infected environment of children are positively correlated with behavioral aggression [25]. In Spain, 585 children with the age ranged 12-18 years from eight schools participated in a study on the role of family relationships in children's aggression versus the family.

Our results showed that family relationships directly affect the violence of children against parents, and the family interaction was the most important aspect of avoiding aggressive behavior [26]. That is, the rich emotional environment of the family is associated with decreased aggressive behaviors in the family and children, while the poor emotional atmosphere of the family correlates with the increased aggressive behaviors of children and members of the family. Therefore, a warm and supportive family environment can be an important factor in increasing family and children's aggressive behaviors.

The results of this study showed a negative correlation between the psychological atmosphere of the family and addiction preparation. In this regard, several studies have shown less experience of drug use among young people with a safe attachment experience [27]. According to Asgari [3], the psychological atmosphere of the family is negatively linked to the tendency toward addiction. This finding is also confirmed by earlier inquiries [3, 28], the results of which are consistent with this finding. According to the findings of the abovementioned studies, the psychological atmosphere of the family is associated with the readiness of children for addiction. The family's warm and intimate atmosphere can play a dissuasive role in preparing children for addiction. Contrary, the family's cold emotional environment can prepare children for addiction.

Furthermore, this study's results showed a negative correlation between the school atmosphere and aggression. Previous studies have also confirmed this finding. For example, a study in India focused on the relationship between aggressive behavior and the school atmosphere in secondary school students. There was a significant negative correlation between school children's aggressive behavior and the atmosphere of the school [29]. An Italian study showed that the socialization of students at school was correlated with the low levels of aggressive behavior [30]. Another research investigated the effect of family factors and the school atmosphere on aggression in the high school students of Gonbad-e-Kavos City.

Results showed that the learning environment and family factors are negatively related to aggression. In this regard, our findings are consistent with [31, 32]. In this case, it is possible to identify the role of the educational environment, classroom, school, peers, and teachers in creating and enhancing students' aggressive behaviors, and the correlation between such behaviors and the atmosphere of the school environment and the classroom. Also, the school environment can be an important deterrent in preventing students' aggressive behaviors. Moreover, the findings revealed a significant negative correlation between the atmosphere of school and addiction preparedness. This is also confirmed by the results of previous studies [33, 34].

On the other hand, the school environment and peer groups play a key role in preparing adolescents for addiction. As the high school students are at a very young age and highly influenced by their peers and friends, peer groups and school environment can play a significant role in preparing adolescents for addiction. Furthermore, the results of this study show a negative correlation between perceived social support and aggression. This conclusion is also confirmed by previous studies. For instance, mental health research on adolescents aged 15 to 19 years tested in five cities, including New Delhi (India), Johannesburg (South Africa), Abuja (Nigeria), Baltimore (United States), and Shanghai (China) showed a negative correlation between perceived social support and aggression [32].

A study examined the mediating effect of social support on the relationship between adolescent violence and family conflicts. The results showed a significant negative correlation between violence and social support [33]. The purpose of the study was to investigate the relationship between aggression and perceived social support in Jordan. Our results also demonstrated a negative correlation between aggression and perceived social support; the perceived family social support was negatively correlated with all areas of aggression [34]. Based on the results of this study and past studies, perceived social support, in particular, the social support of the family can be an effective deterrent agent.

Besides, perceived social support was not correlated with preparation for addiction, based on data analysis and the findings of this research. This result is incompatible with the research that follows. A study investigated the relationship between perceived social support and family functioning in the tendency of students to drug abuse. The results showed a significant negative correlation between perceived social support and the tendency of students to drug abuse. 
Also, family functioning was significantly correlated with the desire of students for drug abuse [35]. Another study was carried out on the relationship between self-efficacy, perceived social support, and drug addiction, among service soldiers. The findings showed that self-efficacy and perceived social help were negatively correlated with drug addiction among Ardabil soldiers [36]. Inconsistency of this finding may be due to the difference in the target community with previous findings. Nevertheless, research on the preparedness of students for addiction revealed other causes than social support.

Concerning the second hypothesis, the results of this study indicate that extraversion as a mediating variable plays a part in the relationship between perceived social support and aggression and the emotional atmosphere, school atmosphere, and the aggression of the family. Also, there is a direct effect in the relationship between the emotional atmosphere of the family and readiness for addiction, as well as the atmosphere of school and readiness for addiction. However, perceived social support did not affect readiness for drug addiction.

Some studies' results are consistent with our findings. Studies have shown that exogenous variables, such as extroversion and task-related factors significantly affect readiness for addiction with a regression coefficient of 0.12 and 0.37 , respectively. Extraversion is a good predictor of the tendency of students to drug abuse, according to the findings of this study [37]. Examining the factors associated with drug use has shown that personality characteristics are among the most important predictors of the use of various substances, such as cigarettes, alcohol, and drugs [38].

Research shows that personality traits significantly contribute as a moderating and causative factor to the onset of drug use. Also, confirmed was the relationship between personality traits and substance use between ages, genders, and cultures. Most studies have consistently shown that it is possible to consider personality tracks as part of substance abuse etiology [39].

As shown, the results of some studies, such as the present study point to the relationship between extraversion and the high score of this personality trait in aggression and drug addiction. Also, some studies show that introversion and a low exorcism score are related to the above variables.

\section{Conclusion}

According to the findings of this study, practical training should be conducted for families to participate in classes and courses, where the educational specialists and psychologists enable families to create a warm and intimate environment and avoid aggressive behaviors and preparedness for addiction among children and all family members. Also, it is possible to educate teachers, trainers, staff, and school directors to create a favorable educational environment and school environment, transform schools into a rich environment for educating students, and prevent aggressive behaviors and preparation for addiction. Finally, by implementing the above strategies, we can significantly increase social support and create a healthy atmosphere for the education of the new generation.

\section{Limitations}

The present study was conducted on male and female students from three high school grades, in five districts of Tehran. Consequently, the research results cannot be generalized to other areas of Tehran and other grades and cities.

\section{Ethical Considerations}

\section{Compliance with ethical guidelines}

Ethical approval for this article has been registered with license No. 805/102483, on December 4, 2019.

\section{Funding}

This research did not receive any grant from funding agencies in the public, commercial, or non-profit sectors.

\section{Authors' contributions}

All authors equally contributed to preparing this article.

\section{Conflict of interest}

The authors declared no conflict of interests.

\section{References}

[1] Choi OJ, Choi J, Kim JH. A longitudinal study of the effects of negative parental child-rearing attitudes and positive peer relationships on social withdrawal during adolescence: an application of a multivariate latent growth model. Int J Adolesc Youth. 2020; 25(1):448-63. [DOI: 10.1080/02673843.2019.1670684]

[2] Dysvic E, Natvig GK, Eikeland OJ, Lindstorm TC. Coping with chronic pain. Int J Nurs Stud. 2005; 42(3):297-305. [DOI: 10.1016/j.ijnurstu.2004.06.009] 
[3] Askari P, Safarzadeh S, Ghasemi Mofrad M. [Relationship of affective family environment and religious orientation with addiction tendency (Persian)]. Stud Islam Psychol. 2011; 5(8):7-26. http:/ / islamicpsy.rihu.ac.ir/article_1086.html

[4] Feist J, Feist GJ. Theories of personality. $7^{\text {th }}$ edition. Boston: McGraw-Hill; 2009. https://www.worldcat.org/title/theories-of-personality/oclc/780795430

[5] Kadivar P. [Educational psychology (Persian)]. 16 $6^{\text {th }}$ edition Tehran: SAMT Publications. 2014. http://samta.samt.ac.ir/ content/9687/

[6] Kaya F, Bilgin H, Singer MI. Contributing factors to aggressive behaviors in high school students in Turkey. J Sch Nurs. 2012; 28(1):56-69.[DOI:10.1177/1059840511418669] [PMID]

[7] Tsitsika AK, Barlou E, Andrie E, Dimitropoulou C, Tzavela EC, Janikian M, Tsolia M. Bullying behaviors in children and adolescents: "An ongoing story". Front Public Health. 2014; 2:7. [DOI:10.3389/fpubh.2014.00007] [PMID] [PMCID]

[8] Estévez E, Jiménez TI, Moreno D. Aggressive behavior in adolescents as a predictor of personal family and school adjustment problems. Psicothema. 2018; 30(1):66-73. [DOI: 10.7334/ psicothema2016.294]

[9] Birnbaum AS, Lytle LA, Hannan PJ, Murray DM, Perry CL, Forster JL. School functioning and violent Behavior among young adolescents: A Contextual analysis. Health Educ Res. 2003; 18(3):389-403. [DOI:10.1093/her/cyf036] [PMID]

[10] Sarafino EP. Health psychology: Biopsychosocial interactions. New York: John Wiley; 2002. https://www.worldcat. org/title/health-psychology-biopsychosocial-interactions/ oclc/469837369

[11] Beyrami M, Movahedi Y, Movahedi M. [The relationship between perceived social support and the feeling of socialemotional loneliness with internet addiction in university students (Persian)]. Social Cognition. 2014; 3(2):109-22. http:// sc.journals.pnu.ac.ir/article_1365.html

[12] Riahi ME, Aliverdinia A, Pourhossein Z. [Investigating the relationship between social support and mental health (Persian)]. Refah J. 2011; 10(39):85-121. http://refahj.uswr.ac.ir/ article-A-10-1-52-1-fa.htm

[13] Eysenck HJ. Pesonality: Biological foundations. In: Verno PA, editor. The Neuropsychology of Individual Differences. London: Academic Press; 1994. https://doi.org/10.1016/ B978-0-12-718670-2.50011-6

[14] Hair J, Black W, Babin BJ, Anderson R. Multivariate data analysis. New Jersey: Pearson; 2010. https:/ / www.scirp.org/ (S(vtj3fa45qm1ean45vvffcz55))/reference/ReferencesPapers. aspx?ReferenceID=1927924

[15] Kaviani H, Pournaseh M, Mousavi AS. [Standardization and validation of the revised form of personality questionnaire in Iran (Persian)]. Iran J Psychiatr Clin Psychol (IJPCP). 2005; 11(3):304-11. http://ijpcp.iums.ac.ir/browse.php?a id $=61 \&$ sid $=1 \&$ slc_lang $=$ en

[16] Zargar Y, Najarian B, Na'ami AZ. [Investigating the relationship between personality characteristics (excitement, assertiveness, and psychological hardiness), religious attitude and marital satisfaction with drug addiction preparation (Persian)]. J Educ Psychol. 2009; 15(1):99-120. https:/ / www.sid. ir/fa/journal/ViewPaper.aspx?id=98530
[17] Shapurian R, Hojat M. Psychometrics characteristics of the Persian version of Eysenck Personality Questionnaire. Psychol Rep. 1985; 57(2):631-9. [DOI:10.2466/pr0.1985.57.2.631]

[18] Bouvard M, Aulard-Jaccod J, Pessonneaux S, Hautekeete M, Rogé B. A study on the abbreviated form of the Eysenck Personality Questionnaire Revised-Abbreviated (EPQR-A) in a student population. Encephale. 2010; 36(6):510-2. [DOI:10.1016/j. encep.2010.02.006] [PMID]

[19] Frasier SD, Hilburn JM, Smith Jr FG. Effect of adolescence on the serum growth hormone response to hypoglycemia. J Pediatr. 1970; 77(3):465-7. [DOI:10.1016/S0022-3476(70)80019-1]

[20] Kouti F, Rajabi GR, Soudani M. [Relationship between family affective atmosphere and social support with general health in school girl students in high school period in Ahwaz (Persian)]. J Social Psychol. 2016; 2(5):4-18.https:/ / www.sid ir/fa/journal/ViewPaper.aspx?ID=192190

[21] Agorastos A, Demiralay C, Huber CG. Influence of religious aspects and personal beliefs on psychological behavior: Focus on anxiety disorders. Psychol Res Behav Manag. 2014; 7:93-101. [DOI:10.2147/PRBM.S43666] [PMID] [PMCID]

[22] Rovai AP, Wighting MJ, Lucking R. The Classroom and School Community Inventory: Development, refinement, and validation of a self-report measure for educational research. Internet High Educ. 2004; 7(4):263-80. [DOI:10.1016/j. iheduc.2004.09.001]

[23] MacCallum RC, Brown MW, Sugawara HM. Power analysis and determination of sample size for covariance structure modeling. Psychol Methods. 1996; 1(2):130-49. https://doi. org/10.1037/1082-989X.1.2.130

[24] Parker JDA, Taylor RN, Eastabrook JM, Schell SL, Wood LM. Problem gambling in adolescence: Relationships with internet misuse, gaming abuse and emotional intelligence. Pers Individ Dif. 2008; 45(2):174-80. [DOI:10.1016/j. paid.2008.03.018]

[25] Javdan M. [The relationship between self-reviewing, family affective atmosphere and life skills with male adolescent aggression (Persian)]. J Person Indiv Diff. 2014; 3(5):125-42. http://jpid.pgu.ac.ir/article_7750.html

[26] Babaei M, Zolghadr A, Nadrlo S, Zolghadr H. [Causes and root of violence among the high school students in Azarshahr city (Persian)]. J Socio-Cult Changes. 2014; 10(4):1-12. http:// journal.aukh.ac.ir/article_527962.html

[27] Ibabe I, Bentler PM. The contribution of family relationships to child- parent violence. J Fam Violence. 2016; 31(2):259-69. [DOI:10.1007/s10896-015-9764-0]

[28] Doyle A, Moretti M. Parent-child relationships and adjustment in adolescence: findings from the HBSC Cycle 3 and NLSCY Cycle 2 Studies [Internet]. 2004 Retrieved from: https:// www.researchgate.net/publication/242230023 Parent-Child_Relationships_and_Adjustment_in_Adolescence_Findings_from_the_HBSC_Cycle_3_and_NLSCY_Cycle_2_Studies.

[29] Masoudnia E, Fallah M. [Investigating the effective social and family factors on the girls running away from home in Yazd (Persian)]. Woman Soc. 2014; 5(1):41-62. http://jzvj. miau.ac.ir/article_514.html 
[30] Kaur D, Niwas R. Aggressive behaviour of secondary school students in relation to school environment. Int J Adv Res (Indore). 2017; 5(5):801-9. [DOI:10.21474/IJAR01/4182 ]

[31] Prati G, Albanesi C, Cicognani E. The relationship between sense of community in the school and students aggressive behavior: A multilevel analysis. Sch Psychol Q. 2018; 33(4):512-6. [DOI:10.1037/spq0000260] [PMID]

[32] Ghayour G, Geravand Y, Asadi Sh, Aghamohammadian Sherbaf HR. [Prognosis of Internet addiction preparation based on parenting and parenting psychosocial style in students (Persian)]. The First International Conference on Management Patterns in the Age of Advancement, 4 July 2017, Tehran. https:/ / profdoc.um.ac.ir/paper-abstract-1062970.html

[33] Cheng Y, Li X, Lou C, Sonenstein FL, Kalamar A, Jejeebhoy $\mathrm{S}$, Delany-Moretlwe $\mathrm{S}$, et al. The association between social support and mental health among vulnerable adolescents in five cities: Findings from the study of the well-being of adolescents in vulnerable environments. J Adolescent Health. 2014 V55(6 Suppl):S31-8. [DOI:10.1016/j.jadohealth.2014.08.020] [PMID]

[34] Bibi N, Malik JA. Effect of social support on the relationship between relational aggression and family-maladjustment: Adolescents' perspective. Pak J Psychol Res. 2016; 31(1):63-76. https:/ / psycnet.apa.org/record/2017-03286-004

[35] Alradaydeh M, Alorani O. The Relationship betweenaggression and perceived social support among university students in Jordan. Int J Humanit Soc Sci. 2017; 7(1):200-5. https://www.researchgate.net/publication/322628694_ The_Relationship_between_Aggression_and_Perceived_Social_Support_among_University_Students_in_Jordan

[36] Massah O, Azkhosh M, Azami Y, Goodiny AA, Doostian Y, Mousavi SH. Students tendency toward illicit drug use: The role of perceived social support and family function in Iran. Iran J Psychiatry Behav Sci. 2017; 11(2):e8314. [DOI:10.17795/ijpbs.8314]

[37] Sadri Damirchi E, Fayazi M, Mohammadi N. [The relationship between self-efficacy and perceived social support with addiction tendency among soldiers (Persian)]. J Mil Med. 2017; 18(4):316-24. http:/ / militarymedj.ir/article-1-1489-en.html

[38] Ketcherside A, Jeon-Slaughter H, Baine JL, Filbey FM. Discriminability of personality profiles in isolated and Co-morbid marijuana and nicotine users. Psychiatry Res. 2016; 238:356-62. [DOI:10.1016/j.psychres.2016.02.024] [PMID] [PMCID]

[39] Zvolensky MJ, Taha F, Bono A, Goodwin RD. Big five personality factors and cigarette smoking: A 10-year study among US adults. J Psychiatr Res. 2015; 63:91-6. [DOI:10.1016/j.jpsychires.2015.02.008] [PMID] [PMCID] 